\title{
Preserved Efficacy of Oral Metronidazole for Severe Clostridium difficile Infection
}

\author{
Shi Nae Yu', Eun Jung Lee ${ }^{2}$ \\ 'Division of Infectious Diseases, Department of Internal Medicine, Soonchunhyang University Cheonan Hospital, Cheonan; ${ }^{2}$ Division of Infectious Diseases, \\ Department of Internal Medicine, Soonchunhyang University Seoul Hospital, Seoul, Korea
}

\begin{abstract}
Objective: Although clinical practice guidelines recommend oral vancomycin for hospitalized patients with severe Clostridium difficile infection (CDI), oral metronidazole is still the preferred regimen due to its tolerability and low cost. In this study, we aimed to compare the clinical efficacy based on clinical cure, recurrence, and 30-day mortality of oral metronidazole and oral vancomycin in treating severe $\mathrm{CDI}$.

Methods: The medical records of patients with the diagnosis of severe CDI in a tertiary hospital in South Korea, between June, 2006 and December, 2013, were analyzed.

Results: A total of 162 severe CDI patients were enrolled for this study: 139 received oral metronidazole and 23 received oral vancomycin. The rate of clinical cure was not significantly different between treatments $(79.86 \%$ for oral metronidazole and $82.61 \%$ for oral vancomycin, $\mathrm{P}>0.99)$. The rate of recurrence was comparable ( $20.77 \%$ vs. $18.18 \%$ for metronidazole and vancomycin, respectively; $\mathrm{P}>0.99)$, as was the rate of 30 -day mortality $(9.35 \%$ vs. $4.35 \%, \mathrm{P}=0.69)$. Risk factors for treatment failure were histamine- 2 antagonist treatment (odds ratio [OR], 4.34; 95\% confidence interval [Cl], 1.64-11.51; $\mathrm{P}=0.0032)$ and fever $(\mathrm{OR}, 2.43 ; 95 \% \mathrm{Cl}, 1.0-5.8$; $\mathrm{P}=0.049$ ).

Conclusion: The clinical efficacy of oral metronidazole for severe CDI was no difference from oral vancomycin, in a real world setting. Oral metronidazole can be a reasonable option for treating severe CDI.
\end{abstract}

Keywords: Clostridium infection; Metronidazole; Vancomycin

\section{INTRODUCTION}

Clostridium difficile infection (CDI) is a healthcare associated infection of growing importance that occurs after prolonged hospitalization and exposure to broad-spectrum antibiotics [1,2]. CDI has a wide range of clinical manifestations, including asymptomatic infection, mild diarrhea, fulminant pseudomembranous colitis (PMC), and even death [3,4]. The incidence and severity of CDI in Korea, is increased in recent years [5]. According to the national wide study, the total incidence of CDI in Korea was 1.7 cases $/ 1,000$ adult admissions in 2004, and 2.7/1,000 adult admissions in 2008 $(\mathrm{P}=0.028)$ [6]. Most clinical practice guidelines recommend oral metronidazole as the initial therapy for the treatment of mild to moderate CDI, then oral vancomycin reserved for severe CDI, or intolerance to or failure to respond to metronidazole treatment $[7,8]$. However, in a real world clinical setting with severe CDI, the question to whom to use oral vancomycin is still a challenging one, due to the risk of emergence of the vancomycin-resistant $\mathrm{en}$ terococci and the high cost of vancomycin $[9,10]$. There is an issue about the over-enrollment of severe CDI with current criteria which suggests potential efficacy of less active agents for these "severe" patients [11] (Table 1): for example, a patient aged over 60 years old presenting with a fever (body temperature $>38.3^{\circ} \mathrm{C}$ ) will be classified as having severe CDI regardless of any co-morbidity. In actual clinical practice, oral metronidazole is prescribed to many patients who would be formally classified as presenting with severe CDI due to its tolerability and low cost. Therefore, we compared the clinical efficacy (clinical cure, recurrence, and 30-day
Correspondence to: Eun Jung Lee

Division of Infectious Disease, Department of Internal Medicine, Soonchunhyang University Seoul Hospital, 59 Daesagwan-ro, Yongsangu, Seoul 04401, Korea

Tel: +82-2-709-9034, Fax: +82-2-709-9594, E-mail: shegets@schmc.ac.kr

Received: May 30, 2018 / Accepted after revision: Jun. 18, 2018
(C) 2018 Soonchunhyang Medical Research Institute This is an Open Access article distributed under the terms of the Creative Commons Attribution Non-Commercial License (http://creativecommons.org/licenses/by-nc/4.0/). 
Table 1. CDI severity scoring system

\begin{tabular}{lc}
\hline CDI severity score & Point \\
\hline Temperature $>38.3^{\circ} \mathrm{C}$ & 1 \\
Age $>60 \mathrm{yr}$ & 1 \\
Albumin $<2.5 \mathrm{mg} / \mathrm{dL}$ & 1 \\
Leukocyte count $>15,000$ cells $/ \mathrm{mm}^{3}$ & 1 \\
Pseudomembranous colitis & 2 \\
Intensive care unit & 2 \\
\hline
\end{tabular}

Patients with $\geq 2$ points were considered to have severe CDI.

CDI, Clostridium difficile infection.

mortality) of oral metronidazole with that of oral vancomycin in patients with severe CDI, and evaluated the risk factors associated with treatment failure.

\section{MATERIALS AND METHODS}

\section{Study design and patients}

This retrospective study was performed at a 749-bed teaching hospital between June 1, 2006 and December 31, 2013. No outpatients were included in this study. Patients with mild to moderate CDI, no treatment, inadequate treatment (other antibiotics, insufficient dose, and insufficient duration) and insufficient information were excluded. The diagnosis of CDI in patients with diarrhea was confirmed by a positive enzyme-linked immunosorbent assay (ELISA) for C. difficile toxins A/B (TOX A/B QUIK CHEK; TECHLAB, Blacksburg, VA, USA). Four hundred and eightythree patients were diagnosed with CDI. Among these patients, a total of 171 patients were included in the study, while the other 312 patients were excluded in accordance with above criteria. Among these 171 patients with severe CDI, nine patients were excluded because they received other treatments (e.g., intravenous metronidazole, oral vancomycin together with intravenous metronidazole, or vancomycin enema) (Fig. 1). We collected baseline characteristics from the patients' medical records, such as age; sex; combined comorbidity; intensive care unit (ICU) admission; the use of antibiotics, immunosuppressive agents, histamine-2 (H2) antagonist, proton pump inhibitor or chemotherapy agents; laboratory findings including white blood cell (WBC) count, serum albumin level, C-reactive protein level; and imaging findings including sigmoidoscope and abdominal X-ray in the case of examinations performed. Patients received either oral metronidazole (500 mg 3 times per day) or oral vancomycin (either $125 \mathrm{mg} 4$ times per day or $250 \mathrm{mg} 3$ times per day) for at least 10 days.

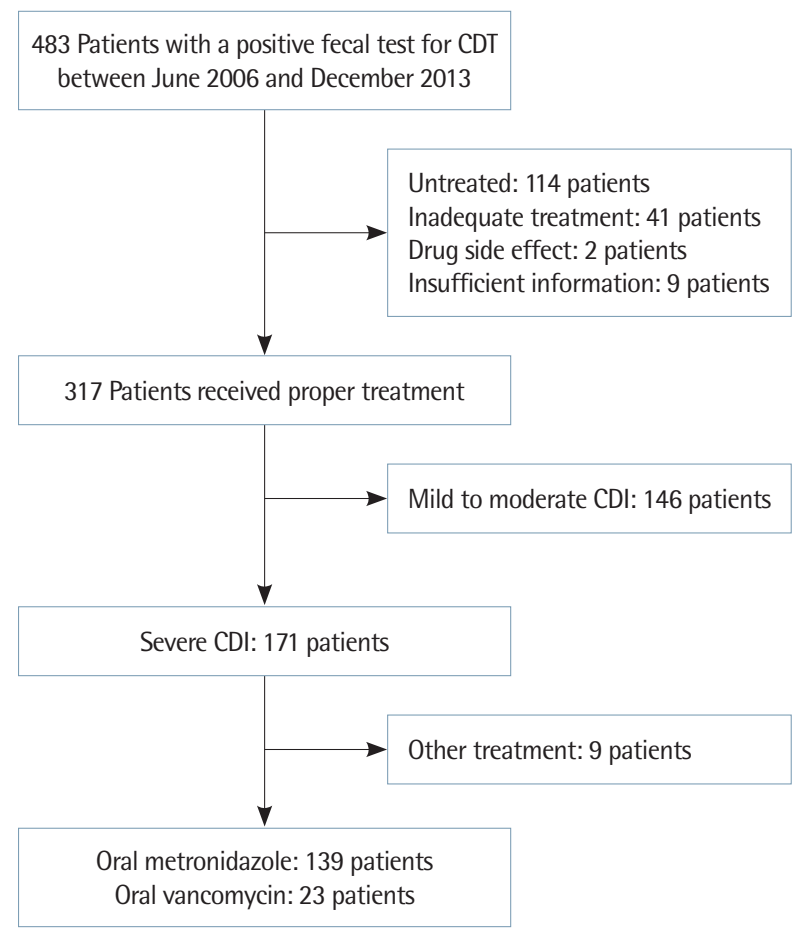

Fig. 1. Flow chart showing the patient selection. CDI, Clostridiusm difficile infection.

The Institutional Review Board of the Soonchunhyang University Hospital approved this study and waived the requirement for informed consent (IRB approval no., 2014-05-010).

\section{Definition}

The severity of CDI was assessed using the CDI severity score system from resource of the American College of Physicians [11] (Table 1). The classification of severity was based on patient data from 2 days before diagnosis until 2 days after diagnosis. The primary outcomes were clinical cure, recurrence, and 30-day mortality. Clinical cure was defined as the resolution of diarrhea by day 6 of treatment and no further requirement for therapy for CDI from the second day after the end of the therapy. Treatment failure was defined as persistence of diarrhea and need for different or additional therapy for CDI, based on the opinion of clinicians. Recurrence was defined as diarrhea recurrence with a positive ELISA result for C. difficile toxin A/B, within 2 months of initial clinical cure [12]. The 30-day mortality was defined as death from any cause within 30 days of a diagnosis of CDI.

\section{Statistical analysis}

All statistical analyses were performed using SAS ver. 9.3 (SAS 
Yu SN, et al. • Oral Metronidazole for Severe Clostridium difficile Infection

Institute Inc., Cary, NC, USA). Patients were divided into an oral metronidazole group and an oral vancomycin group. Comparison of the groups was performed using the independent Student t-test or the Wilcoxon rank sum test for continuous variables, and the chi-square test or Fisher's exact test for categorical variables. To estimate independent risk factors for treatment failure, logistic regression analysis was used. All clinical and laboratory parameters were a prior tested for univariate analysis. The parameters with a

Table 2. Baseline characteristics of patient with severe Clostridiusm difficile infection

\begin{tabular}{|c|c|c|c|}
\hline Characteristic & $\begin{array}{c}\text { Oral } \\
\text { metronidazole } \\
(\mathrm{n}=139)\end{array}$ & $\begin{array}{c}\text { Oral } \\
\text { vancomycin } \\
(n=23)\end{array}$ & P-value \\
\hline Age (yr) & $70.0 \pm 11.8$ & $70.2 \pm 9.77$ & 0.9425 \\
\hline Gender & & & 0.6061 \\
\hline Male & $75(53.6)$ & $11(47.8)$ & \\
\hline Female & $64(46.4)$ & $12(52.2)$ & \\
\hline Diabetes mellitus & $51(36.7)$ & $11(47.8)$ & 0.3088 \\
\hline Hypertension & $79(56.8)$ & $17(73.9)$ & 0.1226 \\
\hline End stage renal disease & $25(18.0)$ & $12(52.2)$ & 0.0003 \\
\hline Cancer & $33(23.7)$ & $6(26.1)$ & 0.8074 \\
\hline $\begin{array}{l}\text { Charlson comorbidity index } \\
\text { (age adjusted) }\end{array}$ & 5.04 & 5.96 & 0.0531 \\
\hline \multicolumn{4}{|l|}{ Antibiotics } \\
\hline Cephalosporin & $33(23.7)$ & $3(13.0)$ & 0.2530 \\
\hline Fluoroquinolone & $6(4.3)$ & $2(8.7)$ & 0.3173 \\
\hline Penicillin & $14(10.1)$ & $4(17.4)$ & 0.2916 \\
\hline Carbapenem & $8(5.8)$ & $2(8.7)$ & 0.6353 \\
\hline Other & $2(1.4)$ & $1(4.3)$ & 0.3703 \\
\hline 2 antibiotics & $46(33.1)$ & $7(30.4)$ & 0.8012 \\
\hline$>2$ antibiotics & $21(15.1)$ & $2(8.7)$ & 0.5346 \\
\hline Immunosuppressive agent & $13(9.4)$ & $1(4.3)$ & 0.6945 \\
\hline Histamine 2 antagonist & $78(56.1)$ & $10(43.5)$ & 0.2598 \\
\hline Proton pump inhibitor & $29(20.9)$ & $5(21.7)$ & $>0.9999$ \\
\hline Chemotherapy & $8(5.8)$ & $2(8.7)$ & 0.6353 \\
\hline Operation & $40(28.8)$ & $6(26.1)$ & 0.7910 \\
\hline L-tube feeding & $47(33.8)$ & $3(13.0)$ & 0.0458 \\
\hline Age (>60 yr) & $117(84.2)$ & $20(87.0)$ & $>0.9999$ \\
\hline Temperature $>38.3^{\circ} \mathrm{C}$ & $59(42.5)$ & $10(43.4)$ & 0.9261 \\
\hline $\begin{array}{l}\text { White blood cell } \\
\qquad\left(>15,000 \text { cells } / \mathrm{mm}^{3}\right)\end{array}$ & $48(34.5)$ & $13(56.5)$ & 0.0438 \\
\hline Albumin (<2.5 mg/dL) & 41 (29.5) & $7(30.4)$ & 0.9273 \\
\hline $\begin{array}{l}\text { Intensive care unit stay at } \\
\text { diagnosis }\end{array}$ & $40(28.8)$ & $5(21.7)$ & 0.4852 \\
\hline C-reactive protein (mg/L) & $6.18(3.00-11.56)$ & 7.78 (2.69-14.99) & 0.4437 \\
\hline $\begin{array}{l}\text { Presence of pseudomembranous } \\
\text { colitis }\end{array}$ & $26(18.7)$ & $8(34.8)$ & 0.2045 \\
\hline Presence of ileus & $28(20.0)$ & $4(17.4)$ & 0.6409 \\
\hline
\end{tabular}

Values are presented as mean \pm standard deviation, number (\%), or median (interquartile range), unless otherwise stated.
P-value of less than 0.1 and those with potentially biologic meanings were considered in a multivariate analysis. A P-value of $<0.05$ was considered to be statistically significant.

\section{RESULTS}

\section{Patient characteristics and clinical outcomes}

A total of 162 patients with severe CDI were studied: 139 patients received oral metronidazole, and 23 patients received oral vancomycin. Table 2 reports the characteristics of the study populations. The mean age of the patients was $70.0 \pm 11.5$ years. Eightysix patients were male. There was no significant difference between oral metronidazole group and oral vancomycin group in terms of age adjusted Charlson comorbidity index (oral metronidazole, 5.04; oral vancomycin, 5.96; $\mathrm{P}=0.053$ ). Oral vancomycin group showed more proportion of diagnosis of end stage renal disease and higher WBC level. There were no patients with vancomycin-resistant enterococci in the oral vancomycin group. A total of 46 patients (oral metronidazole, 34 patients; oral vancomycin, 12 patients) underwent sigmoidoscope. The result of examination was PMC in 41 patients (oral metronidazole, 29 patients; oral vancomycin, 12 patients).

The overall clinical outcomes are shown in Fig. 2. The clinical cure rate was $79.86 \%$ (111 of 139 patients) in patients receiving oral metronidazole and $82.61 \%$ (19 of 23 patients) in those receiving oral vancomycin $(\mathrm{P}>0.99)$. Following treatment failure of oral metronidazole, clinical cure was achieved by changing to treatment with oral vancomycin $(n=23,82.14 \%)$, intravenous metronidazole $(n=3,10.71 \%)$, or both oral vancomycin and intravenous metronidazole $(n=2,7.14 \%)$. The recurrence of CDI occurred in 27 of 139 patients (20.77\%) treated with metronidazole and in four

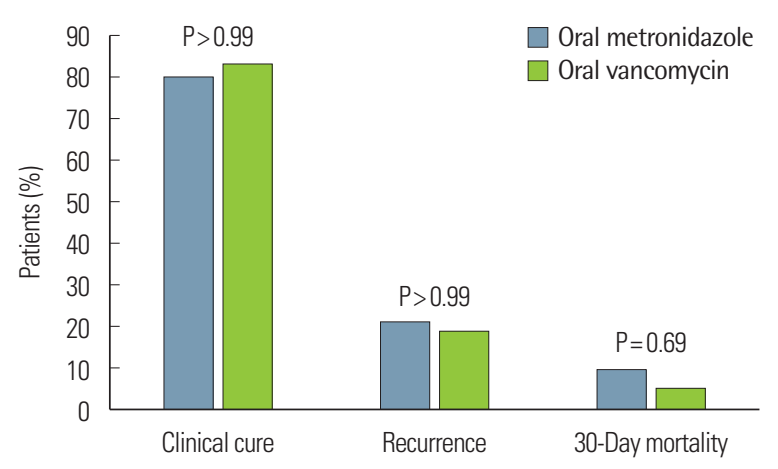

Fig. 2. Clinical efficacy between oral metronidazole and oral vancomycin in severe CDI. 
of 23 patients (18.18\%) treated with oral vancomycin $(\mathrm{P}>0.99)$. There was no significant difference between oral metronidazole and oral vancomycin treatment in the rate of 30-day mortality (9.35\% [13 of 139 patients] vs. $4.35 \%$ [one of 23 patients], $\mathrm{P}=0.69$ ). Only one case with oral metronidazole was CDI-related death. The patient expired due to CDI with neutropenia during hospitalization for gastric cancer treatment.

\section{Factors associated with treatment failure in severe Clostridium difficile infection patients}

We analyzed the characteristics of severe CDI patients with respect to whether they had treatment failure. Age; gender; diagnosis of diabetes mellitus, hypertension, or end stage renal disease; ICU admission; duration of ICU stay; use of any antibiotics; antibiotic maintenance during treatment; use of an immunosuppressive agent; use of a proton pump inhibitor; use of a chemotherapy agent; operation; serum albumin level; WBC level; finding of PMC on sigmoidoscope; and finding of ileus on simple abdominal X-ray were not related to treatment failure. In addition, the type of medication for treatment of CDI was not related to treatment failure. We analyzed the variables that showed trend towards being related to treatment failure $(\mathrm{P}<0.1)$ with multivariate analysis. The use of $\mathrm{H} 2$ antagonist $(\mathrm{P}=0.0032$; odds ratio $[\mathrm{OR}], 4.34 ; 95 \%$ confidence interval [CI], 1.64-11.51) and the presence of a fever (body temperature $>38.3^{\circ} \mathrm{C}: \mathrm{P}=0.049$; $\mathrm{OR}, 2.4 ; 95 \% \mathrm{CI}, 1.0-5.86$ ) were found to be significantly correlated with treatment failure (Table 3 ).

\section{DISCUSSION}

The Society for Healthcare Epidemiology of America/Infectious Diseases Society of America guideline and the American Gastroenterology Association recommend oral vancomycin as the first-line agent for the treatment of severe CDI patients [7,13].

Table 3. Multivariate analysis of risk factors for treatment failure in severe Clostridiusm difficile infection

\begin{tabular}{lcc}
\hline Variable & $\begin{array}{c}\text { Odds ratio } \\
\text { (95\% confidence interval) }\end{array}$ & P-value \\
\hline Cancer & $0.483(0.144-1.612)$ & 0.2365 \\
Duration of hospital stay & $0.981(0.962-1.000)$ & 0.0481 \\
Histamine 2 antagonist & $4.339(1.635-11.512)$ & 0.0032 \\
L-tube feeding & $1.824(0.731-4.553)$ & 0.1979 \\
Temperature $>38.3^{\circ} \mathrm{C}$ & $2.427(1.005-5.858)$ & 0.0486 \\
C-reactive protein & $0.999(0.990-1.009)$ & 0.8780 \\
\hline
\end{tabular}

Oral metronidazole treatment is generally considered to be less effective than oral vancomycin treatment, because cases of elderly patients with severe comorbidities are increasing, and because the use of broad-spectrum antibiotics (new fluoroquinolones and cephalosporins) is also increasing [14-16]. Metronidazole resistance, the emergence of the BI/NAP1/027 (ribotype 027) strain of C. difficile, and poor concentration of oral metronidazole in colon are also potential causes of the decreasing efficacy of oral metronidazole.

The emergence of the hypervirulent BI/NAP1/027 (ribotype 027) strain of $C$. difficile is associated with more severe disease due to increased toxin production. In 2009, Tae et al. [17] reported the first case of $C$. difficile polymerase chain reaction (PCR) ribotype 027 infection refractory to oral metronidazole therapy in Korea. However, the proportion of this hypervirulent strain is low [18]. Kim et al. [19] performed a prospective study that found that binary toxin-producing C. difficile infection, including ribotype 027, was not common in Korea and that these isolates were highly susceptible to metronidazole and vancomycin.

Metronidazole-resistant strains of C. difficile are rare. In 1999, for the first time, Wong et al. [20] detected a metronidazole-resistant strain of $C$. difficile in a patient with CDI. In Korea, Kim et al. [21] reported that no metronidazole resistance was detected. Metronidazole resistance does not appear to be increasing [22]. Therefore, the emergence of the BI/NAP1/027 strain and metronidazole resistance does not have a critical influence on the efficacy of oral metronidazole treatment in severe CDI patients in Korea.

The antibiotic concentration in the colon is very important for the treatment for CDI. The difference in treatment effect for CDI between oral metronidazole and oral vancomycin is due to the difference in the absorption rate in the colon. When oral metronidazole is administered, it is absorbed rapidly and almost completely, with only $6 \%-15 \%$ of the drug metabolites excreted in the stool. This concentration rate of metronidazole in stool reflects the rate of its secretion in the colon. Once treatment of CDI is initiated, the stool concentration rate of metronidazole decreases rapidly from $9.3 \mu \mathrm{g} / \mathrm{g}$ in watery stools to $1.2 \mu \mathrm{g} / \mathrm{g}$ in formed stools [23]. In asymptomatic $C$. difficile carriers, metronidazole is not detected in stool [24]. In contrast, oral vancomycin is poorly absorbed; thus, fecal concentrations are maintained throughout treatment. Johnson et al. [24] reported that the fecal concentration rate after oral vancomycin administration (125 mg administered 4 times daily) is generally $>1,000 \mu \mathrm{g} / \mathrm{g}$. Oral metronidazole treatment is report- 
Yu SN, et al. • Oral Metronidazole for Severe Clostridium difficile Infection

ed to fail, because the concentration of metronidazole in colon was slowly increased but was not maintained at a consistent rate in colon $[10,22,25]$. If a patient shows no clinical response to oral metronidazole, clinicians should consider changing medications (e.g., oral vancomycin or intravenous metronidazole). In our study, all treatment failure patients receiving oral metronidazole achieved a clinical cure after switching to oral vancomycin or intravenous metronidazole.

Especially, patients with severe complicated CDI, with symptoms including hypotension, shock, and/or megacolon, do not have enough time to wait until metronidazole treatment will take effect and a clinical cure will be achieved [7]. Thus, severe complicated CDI patients should be treated in accordance with current clinical practice guidelines, based on high dose vancomycin (500 mg 4 times daily) [7].

In our study, $\mathrm{H} 2$ antagonist treatment and fever (body temperature $>38.3^{\circ} \mathrm{C}$ ) were related to treatment failure. There are some reports supporting the association between $\mathrm{H} 2$ antagonist therapy and CDI treatment failure. The mechanism of how $\mathrm{H} 2$ antagonist exposure contributes to an increased risk of CDI treatment failure is not yet clear. However, it is strongly suspected that the effect of $\mathrm{H} 2$ antagonist in suppressing gastric acid secretion aids the survival of C. difficile [26-28]. Dial et al. [29] reported that the use of acid-suppressive therapy is associated with an increased risk of CDI. However, Jung et al. [30] did not find an association between the use of $\mathrm{H} 2$ antagonist and metronidazole treatment failure. Further studies on the role of acid-suppressive therapy in CDI treatment appear to be necessary.

This study had some limitations: it was retrospective, taking place in a single tertiary medical center. The number of patients was relatively small. In addition, the hospital used a toxin assay for diagnosis, which is less sensitive than diagnosis by $C$. difficile PCR and $C$. difficile culture.

In conclusion, we found that in treating severe CDI patients, oral metronidazole was an effective treatment in addition to oral vancomycin. Therefore, oral metronidazole can be viewed as a valid clinical option for treating not only patients with mild to moderate CDI but also those with severe CDI.

\section{REFERENCES}

1. Fekety R, Shah AB. Diagnosis and treatment of Clostridium difficile colitis. JAMA 1993;269:71-5.

2. Kelly CP, Pothoulakis C, LaMont JT. Clostridium difficile colitis. N Engl J
Med 1994;330:257-62.

3. Larson HE, Price AB, Honour P, Borriello SP. Clostridium difficile and the aetiology of pseudomembranous colitis. Lancet 1978;1:1063-6.

4. Bartlett JG, Chang TW, Gurwith M, Gorbach SL, Onderdonk AB. Antibiotic-associated pseudomembranous colitis due to toxin-producing clostridia. N Engl J Med 1978;298:531-4.

5. Byun TJ, Han DS, Ahn SB, Cho HS, Kim TY, Eun CS, et al. Clinical characteristics and changing epidemiology of Clostridium difficile-associated disease (CDAD). Korean J Gastroenterol 2009;54:13-9.

6. Kim YS, Han DS, Kim YH, Kim WH, Kim JS, Kim HS, et al. Incidence and clinical features of Clostridium difficile infection in Korea: a nationwide study. Epidemiol Infect 2013;141:189-94.

7. Cohen SH, Gerding DN, Johnson S, Kelly CP, Loo VG, McDonald LC, et al. Clinical practice guidelines for Clostridium difficile infection in adults: 2010 update by the society for healthcare epidemiology of Ameri$\mathrm{ca}$ (SHEA) and the infectious diseases society of America (IDSA). Infect Control Hosp Epidemiol 2010;31:431-55.

8. Zar FA, Bakkanagari SR, Moorthi KM, Davis MB. A comparison of vancomycin and metronidazole for the treatment of Clostridium difficile-associated diarrhea, stratified by disease severity. Clin Infect Dis 2007;45: 302-7.

9. Gerding DN. Is there a relationship between vancomycin-resistant enterococcal infection and Clostridium difficile infection? Clin Infect Dis 1997;25 Suppl 2:S206-10.

10. Al-Nassir WN, Sethi AK, Nerandzic MM, Bobulsky GS, Jump RL, Donskey CJ. Comparison of clinical and microbiological response to treatment of Clostridium difficile-associated disease with metronidazole and vancomycin. Clin Infect Dis 2008;47:56-62.

11. Turner BJ, Williams D, Taichman D, Hessen MT. In the clinic: Clostridium difficile infection. Philadelphia (PA): American College of Physicians; 2010.

12. Louie TJ, Miller MA, Mullane KM, Weiss K, Lentnek A, Golan Y, et al. Fidaxomicin versus vancomycin for Clostridium difficile infection. N Engl J Med 2011;364:422-31.

13. Surawicz CM, Brandt LJ, Binion DG, Ananthakrishnan AN, Curry SR, Gilligan PH, et al. Guidelines for diagnosis, treatment, and prevention of Clostridium difficile infections. Am J Gastroenterol 2013;108:478-98.

14. McCusker ME, Harris AD, Perencevich E, Roghmann MC. Fluoroquinolone use and Clostridium difficile-associated diarrhea. Emerg Infect Dis 2003;9:730-3.

15. Gerding DN. Clindamycin, cephalosporins, fluoroquinolones, and Clostridium difficile-associated diarrhea: this is an antimicrobial resistance problem. Clin Infect Dis 2004;38:646-8.

16. Gaynes R, Rimland D, Killum E, Lowery HK, Johnson TM 2nd, Killgore $\mathrm{G}$, et al. Outbreak of Clostridium difficile infection in a long-term care facility: association with gatifloxacin use. Clin Infect Dis 2004;38:640-5.

17. Tae CH, Jung SA, Song HJ, Kim SE, Choi HJ, Lee M, et al. The first case of antibiotic-associated colitis by Clostridium difficile PCR ribotype 027 in Korea. J Korean Med Sci 2009;24:520-4.

18. Kim J, Kang JO, Kim H, Seo MR, Choi TY, Pai H, et al. Epidemiology of Clostridium difficile infections in a tertiary-care hospital in Korea. Clin Microbiol Infect 2013;19:521-7.

19. Kim J, Seo MR, Kang JO, Choi TY, Pai H. Clinical and microbiologic characteristics of Clostridium difficile infection caused by binary toxin producing strain in Korea. Infect Chemother 2013;45:175-83.

20. Wong SS, Woo PC, Luk WK, Yuen KY. Susceptibility testing of Clostridium difficile against metronidazole and vancomycin by disk diffusion and Etest. Diagn Microbiol Infect Dis 1999;34:1-6.

21. Kim J, Kang JO, Pai H, Choi TY. Association between PCR ribotypes and 
antimicrobial susceptibility among Clostridium difficile isolates from healthcare-associated infections in South Korea. Int J Antimicrob Agents 2012;40:24-9.

22. Tart SB. The role of vancomycin and metronidazole for the treatment of Clostridium difficile-associated diarrhea. J Pharm Pract 2013;26:488-90.

23. Bolton RP, Culshaw MA. Faecal metronidazole concentrations during oral and intravenous therapy for antibiotic associated colitis due to Clostridium difficile. Gut 1986;27:1169-72.

24. Johnson S, Homann SR, Bettin KM, Quick JN, Clabots CR, Peterson LR, et al. Treatment of asymptomatic Clostridium difficile carriers (fecal excretors) with vancomycin or metronidazole: a randomized, placebo-controlled trial. Ann Intern Med 1992;117:297-302.

25. Pepin J. Vancomycin for the treatment of Clostridium difficile infection: for whom is this expensive bullet really magic? Clin Infect Dis 2008;46: 1493-8.
26. Kim JW, Lee KL, Jeong JB, Kim BG, Shin S, Kim JS, et al. Proton pump inhibitors as a risk factor for recurrence of Clostridium-difficile-associated diarrhea. World J Gastroenterol 2010;16:3573-7.

27. Kim YG, Graham DY, Jang BI. Proton pump inhibitor use and recurrent Clostridium difficile-associated disease: a case-control analysis matched by propensity score. J Clin Gastroenterol 2012;46:397-400.

28. Turco R, Martinelli M, Miele E, Roscetto E, Del Pezzo M, Greco L, et al. Proton pump inhibitors as a risk factor for paediatric Clostridium difficile infection. Aliment Pharmacol Ther 2010;31:754-9.

29. Dial S, Delaney JA, Barkun AN, Suissa S. Use of gastric acid-suppressive agents and the risk of community-acquired Clostridium difficile-associated disease. JAMA 2005;294:2989-95.

30. Jung KS, Park JJ, Chon YE, Jung ES, Lee HJ, Jang HW, et al. Risk factors for treatment failure and recurrence after metronidazole treatment for Clostridium difficile-associated diarrhea. Gut Liver 2010;4:332-7. 